\title{
Lack of bystander activation shows that localization exterior to chromosome territories is not sufficient to up-regulate gene expression
}

\author{
Céline Morey, ${ }^{1}$ Clémence Kress, ${ }^{2}$ and Wendy A. Bickmore ${ }^{3}$ \\ MRC Human Genetics Unit, Edinburgh EH4 2XU, Scotland, United Kingdom
}

\begin{abstract}
Position within chromosome territories and localization at transcription factories are two facets of nuclear organization that have been associated with active gene expression. However, there is still debate about whether this organization is a cause or consequence of transcription. Here we induced looping out from chromosome territories (CTs), by the activation of Hox loci during differentiation, to investigate consequences on neighboring loci. We show that, even though flanking genes are caught up in the wave of nuclear reorganization, there is no effect on their expression. However, there is a differential organization of active and inactive alleles of these genes. Inactive alleles are preferentially retained within the CT, whereas actively transcribing alleles, and those associated with transcription factories, are found both inside and outside of the territory. We suggest that the alleles relocated further to the exterior of the CT are those that were already active and already associated with transcription factories before the induction of differentiation. Hence active gene regions may loop out from CTs because they are able to, and not because they need to in order to facilitate gene expression.
\end{abstract}

[Supplemental material is available online at www.genome.org.]

Gene organization along the primary DNA sequence of mammalian genomes is not random. Genes that, for the most part, are functionally unrelated, cluster in the genome and selection has acted to prevent these clusters from becoming fragmented during evolution (Singer et al. 2005). The genes in these clusters tend to be expressed at high levels (Caron et al. 2001) and/or in a wide range of tissues (Lercher et al. 2002). Moreover, reporter genes are also expressed at higher levels when inserted into these domains compared with other genomic regions (Gierman et al. 2007). It has been suggested that gene clustering facilitates transcriptional activation by creating regions of open decondensed chromatin (Sproul et al. 2005). Similarly, colocalization of active genes at focal concentrations of RNA polymerase II (transcription factories) or splicing factors (splicing speckles) may enhance the efficiency of gene expression (Shopland et al. 2003; Osborne et al. 2004; Fraser and Bickmore 2007; Brown et al. 2008). Indeed, nuclear clustering of gene-rich domains, both in cis and in trans, has been detected by diverse techniques (Shopland et al. 2006; Simonis et al. 2006). Many of these gene-rich domains have also been seen to adopt positions at the edge or outside of chromosome territories (CTs) - termed looping out, but regardless of the activity of individual genes within them (Mahy et al. 2002; Brown et al. 2006). Hence, it remains unclear whether there is a causal relationship between CT reorganization and transcription. In one case, an increased frequency of looping out, induced by the insertion of a beta-globin LCR, did accompany increased association of the flanking genes with transcription factories and an activation of some gene expression (Noordermeer et al. 2008).

\footnotetext{
Present addresses: 'Institut Pasteur, Roux 75015, Paris, France: 2Institut National de la Recherche Ágronomique, 78352 Jouy-enJosas Cedex, France.

${ }^{3}$ Corresponding author.

E-mail W.Bickmore@hgu.mrc.ac.uk; fax 44-131-467-8456.

Article published online before print. Article and publication date are at http://www.genome.org/cgi/doi/10.1101/gr.089045.108.
}

Gene clusters where intra-CT organization most closely correlates with expression are those that contain functionally related and coregulated genes. When silent, these clusters, which are mainly located inside of CTs, upon induction of expression will relocate more toward the outside of CTs (Volpi et al. 2000; Williams et al. 2002). Examples of such gene clusters are the murine Hoxb and Hoxd loci. CT reorganization accompanies their induction, both during the differentiation of embryonic stem (ES) cells and also along the anterior-posterior axis of the developing embryo (Chambeyron and Bickmore 2004; Chambeyron et al. 2005; Morey et al. 2007). However, the absence of looping out of Hoxd from its CT in the limb bud (Morey et al. 2007), and the ability of a transposed Hoxb1 to induce some looping out in the absence of transcription (Morey et al. 2008), question the absolute requirement for this facet of nuclear reorganization in promoting gene expression.

Paralogous mammalian Hox loci evolved by duplication of an ancestral cluster during vertebrate radiation (Ferrier and Minguillon 2003). The apparent similarity in the nuclear behavior of Hoxb and Hoxd occurs despite the very different genomic contexts within which they are found. Hoxd is within an extensive gene desert. Aside from the closely linked $M t x 2$, Evx2, and Lnp, there are no other annotated genes for 600-700 kilobases $(\mathrm{kb}) 3^{\prime}$ or $5^{\prime}$ of Hoxd. In contrast, Hoxb is embedded in a gene-dense region, flanked by many unrelated genes (Fig. 1). This raises interesting questions as to how genomic environments impact the expression and nuclear organization of Hox loci and, conversely, how activation and reorganization of these Hox loci affects the flanking genes and genomic regions.

Using DNA-fluorescence in situ hybridization (FISH), coupled with gene expression analysis during ES cell differentiation, we show that intra-CT reorganization, initiated within Hox clusters, then spreads out for hundreds of kilobases into adjacent genomic regions that, in the case of $H o x b$, contain many unrelated genes. We show that the expression of these flanking genes is not affected by their being swept up in extensive CT reorganization. Using 
A

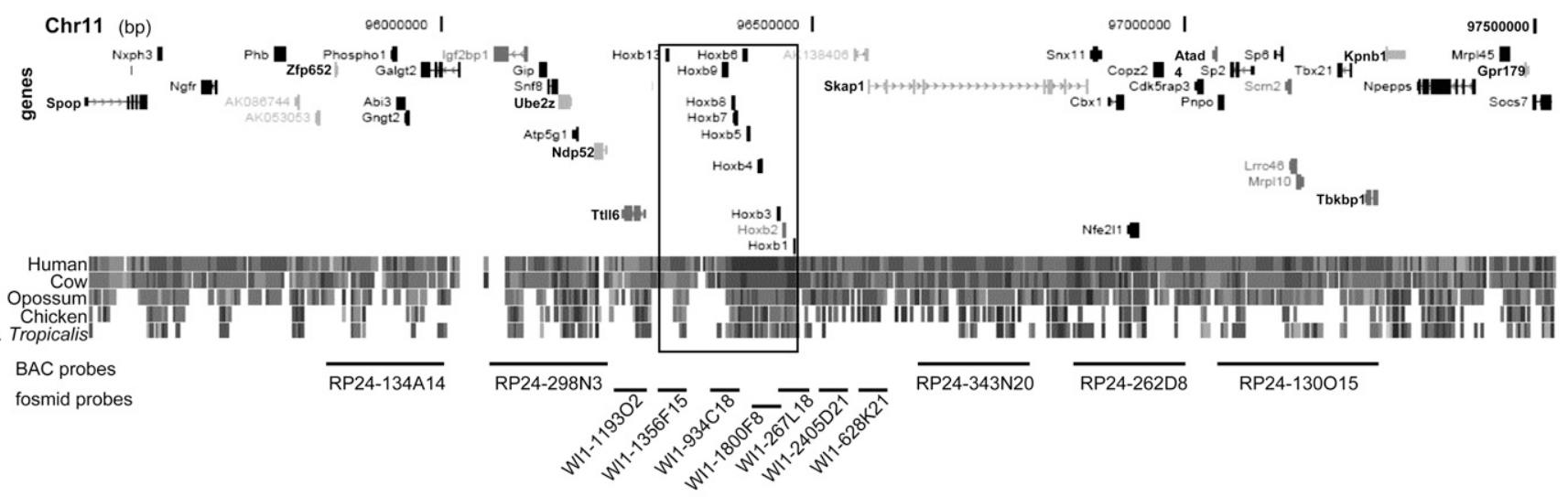

B

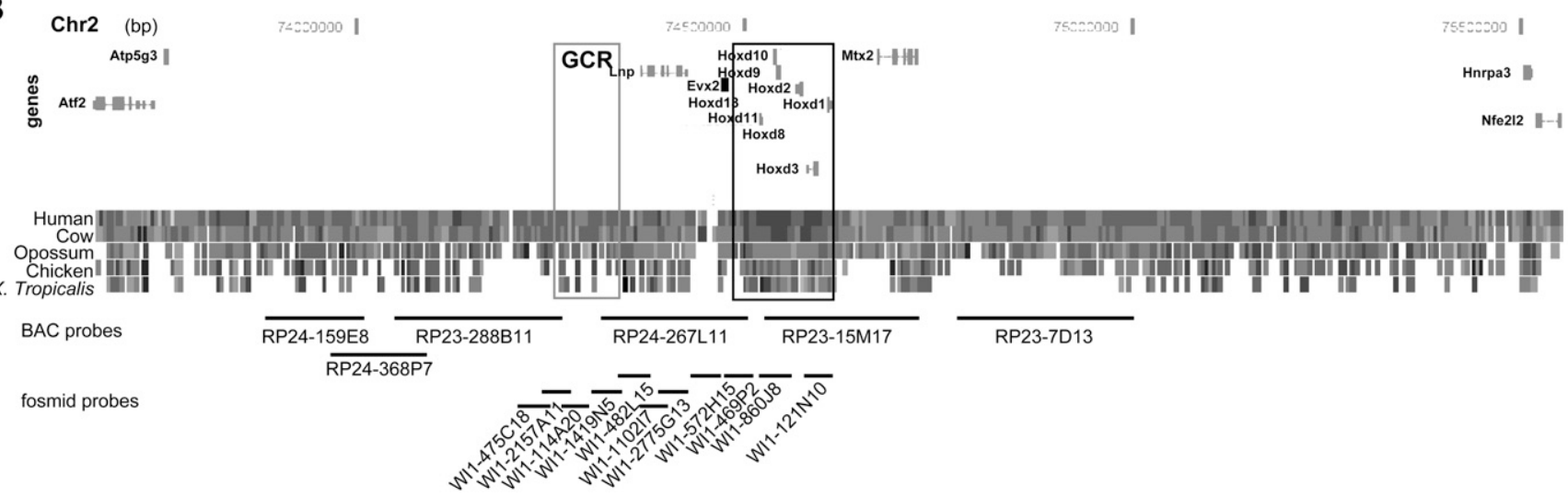

Figure 1. Comparative genomic structure of Hoxb and Hoxd. Map of the $2 \mathrm{Mb}$ genomic regions surrounding Hoxb on MMU11 ( $A$ ) and surrounding Hoxd on MMU2 $(B)$ showing the position of genes, the level of conservation between the murine locus and other vertebrates, and the position of BACs and fosmids used as probes in this study (Supplemental Table S1). The Hoxb and Hoxd loci are boxed in black. The gray box locates a region of noncoding sequence conservation that includes the global control region (GCR). Data and map positions (bp) are taken from the August 2005 NCBI Build 35 of the mouse genome (http://genome.ucsc.edu/cgi-bin/hgGateway) and from Ensembl v37, February 2006 (http://www.ensembl.org/Mus_musculus/index.html).

RNA-FISH we show that inactive and active alleles of these flanking genes do differ in their intra-CT distribution, with inactive alleles preferentially retained within the CT. However, the actively transcribing alleles locate inside, at the edge, and outside of the CT. Similarly, by immuno-FISH we show that the association of gene loci with transcription factories is preferentially, but not exclusively, seen toward the edge and outside of the CT. The alleles that are relocated further to the exterior of the CT appear to be those that were already active and that were already associated with transcription factories. We suggest that silent Hox loci are restrained to localizations inside of CTs and that, upon their activation, a change in long-range chromatin structure releases this constraint. This then allows enough freedom of movement for the chromatin of a large genomic region, which includes not just the Hox loci but also flanking genes, to be able to now locate in many positions relative to the CT.

\section{Results}

Distinct nuclear behaviors of Hoxb and Hoxd regions in undifferentiated cells

In undifferentiated ES cells, silent Hox clusters are preferentially located at the edge or inside of their CTs (Chambeyron and Bickmore 2004; Morey et al. 2007). To determine if this is a feature intrinsic to Hox clusters themselves, or whether it is influenced by the flanking genomic regions, we used 2D FISH on nuclei of undifferentiated OS25 ES cells to measure the intra-CT position of signals from probe pairs covering $>1 \mathrm{Mb}$ around Hoxb and Hoxd (Figs. 1, 2A; Supplemental Table S1).

The whole Hoxd region, including flanking gene deserts, located well inside the MMU2 CT ( $\geq 60 \%$ alleles at distance $>0.4$ $\mu \mathrm{m})$ with $<15 \%$ of alleles found outside (Fig. $2 \mathrm{~B}$ ). A different picture was seen at Hoxb where, consistent with previous studies (Chambeyron and Bickmore 2004), significantly more loci ( 30\%) were seen outside of the respective CT than at Hoxd $\left(P<10^{-3}\right)$. This was especially pronounced at the $5^{\prime}$ end of the cluster and extends to the $5^{\prime}$ flanking region ( $>40 \%$ alleles $<-0.2 \mu \mathrm{m}$ ).

This difference in nuclear organization between Hoxb and Hoxd may reflect the activity of the surrounding regions. To investigate this we hybridized cDNA from undifferentiated ES cells to a mouse 38K cDNA array (GEO accession: GSE15166) and to a custom tiling array for the Hoxb and Hoxd loci and their surrounding regions (Fig. 2C; Supplemental Table S2).

As previously assessed by RT-PCR (Chambeyron and Bickmore 2004; Chambeyron et al. 2005; Morey et al. 2007), Hoxb and Hoxd genes were expressed either very weakly, or not at all. In contrast, high steady-state levels of transcripts were detected for some genes $5^{\prime}$ (Igf2bp1, Snf8, Ube2z, and Ndp52) and 3' (Nfe2l1) of Hoxb. 


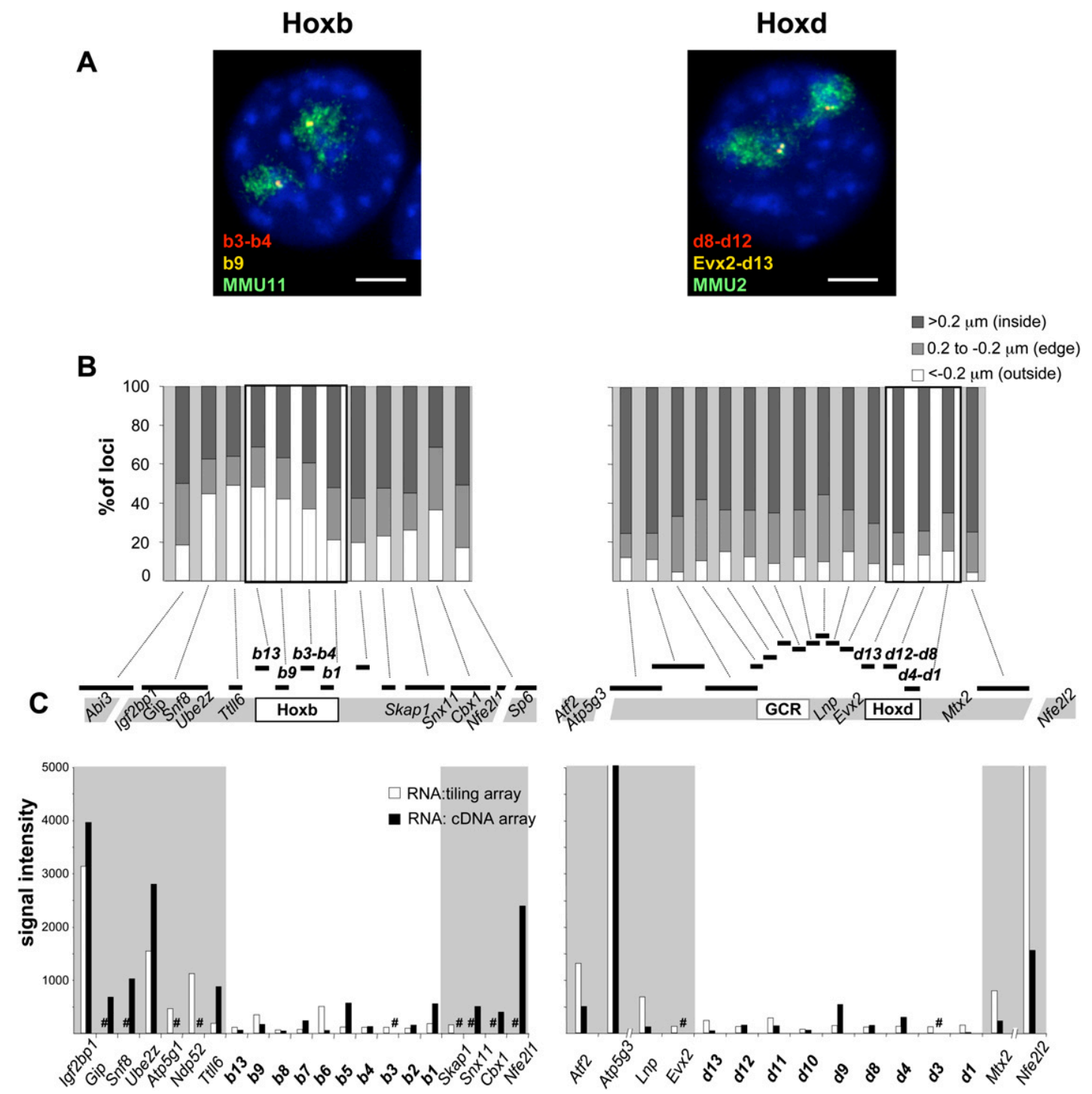

Figure 2. Nuclear organization and gene expression at Hoxb and Hoxd in undifferentiated ES cells. (A) Four-color DNA-FISH on DAPI counterstained nuclei from undifferentiated OS25 ES cells using; (left panel) fosmid probes WI1-1800F8 (b3-b4, red), WI1-934C18 (b9, yellow), and an MMU11 chromosome paint (green) and (right panel) fosmid probes WI1-860/8 (d8-d12, red), WI1-469P2 (Evx2-d13, yellow), and an MMU2 chromosome paint (green). Bar, $5 \mu \mathrm{m}$. (B) Percentage of Hoxb or Hoxd region signals located either inside ( $>0.2 \mu \mathrm{m}$; dark gray bars), at the edge ( $\pm 0.2 \mu \mathrm{m}$; light gray bars) or outside ( $<-0.2 \mu \mathrm{m}$; white bars) of the respective CT edge. The location of the probes is depicted on the map underneath the histograms. A minimum of 50 nuclei/100 territories was analyzed. (C) Intensities of signals of CDNA from undifferentiated OS25 ES cells hybridized on a tiling microarray (white columns) or on a cDNA microarray (black columns). Combined results from three independent experiments, including a dye swap, are shown. A sharp sign indicates genes not represented on the respective array.

Hence, the differential CT organization of Hoxb and Hoxd before differentiation likely reflects the transcriptional activity of the genes flanking Hoxb.

Chromosome territory reorganization during ES cell differentiation extends out to the regions that surround Hox loci

When activated during ES cell differentiation, an increased frequency of Hox alleles are seen at positions outside of their CTs, as measured either by 2D FISH in differentiating ES cells, or by 3D FISH in differentiating ES cells and in the embryo proper (Chambeyron and Bickmore 2004; Chambeyron et al. 2005;
Morey et al. 2007). To determine if this level of nuclear reorganization is restricted just to the Hox genes themselves, or whether it spreads further, we analyzed the position, relative to the CT edge, of hybridization signals from probes across the genomic regions, in ES cells that had been differentiated for 3 and $7 \mathrm{~d}$ (Fig. 3A,B). As previously reported (Chambeyron and Bickmore 2004), the most extensive looping out was seen at the early stages of differentiation (D3) and at the 3' end of Hoxb. This decreased by day 7 and, at this time point, looping out had spread to the 5 ' end of $H o x b$. A significant relocalization further to the outside of the CT also spreads $>500 \mathrm{~kb} 3^{\prime}$ of $H o x b$ into the flanking gene regions. No additional CT reorganization was detected for the 5' flanking domain, which is already mainly located outside, or at the edge, of 
the CT in undifferentiated cells. This was reconfirmed in 3D FISH of pFa-fixed cells (Fig. 3C). However, the absolute percentages of Hoxb1, Igf $2 b p 1$, or Cbx1 signals located outside, or at the edge, of the CT during differentiation were lower than those measured by 2D FISH. This suggests that, as we have previously described (Morey et al. 2007), methanol/acetic acid fixation of 2D FISH exaggerates the nuclear movements compared to $\mathrm{pFa}$ fixation.

At Hoxd, CT reorganization also spreads 3' over Mtx2 and 5' over Lnp (Fig. 3A,B; Morey et al. 2007). In the 5' direction, FISH signals from all fosmids from WI1-1102I7 through to WI12157A11 (Fig. 1) showed significant movement toward the edge of the CT $(P<0.05)$ at D3 of differentiation (Fig. 3). However, there was no significant reorganization $(P=0.165)$ detected with the next clone-WI1-475C18. Intriguingly, this boundary to the spread of CT reorganization $5^{\prime}$ of Hoxd corresponds to the end of a long-range regulatory region termed the GCR. As at Hoxb, the extent of intra-CT reorganization of Hoxd, decreased by D7.

\section{The spread of CT reorganization does not affect expression of flanking genes}

To test whether the spreading of CT reorganization to the genomic regions flanking Hox clusters impacts the expression of genes located there, we analyzed gene expression after D3 of differentiation
A

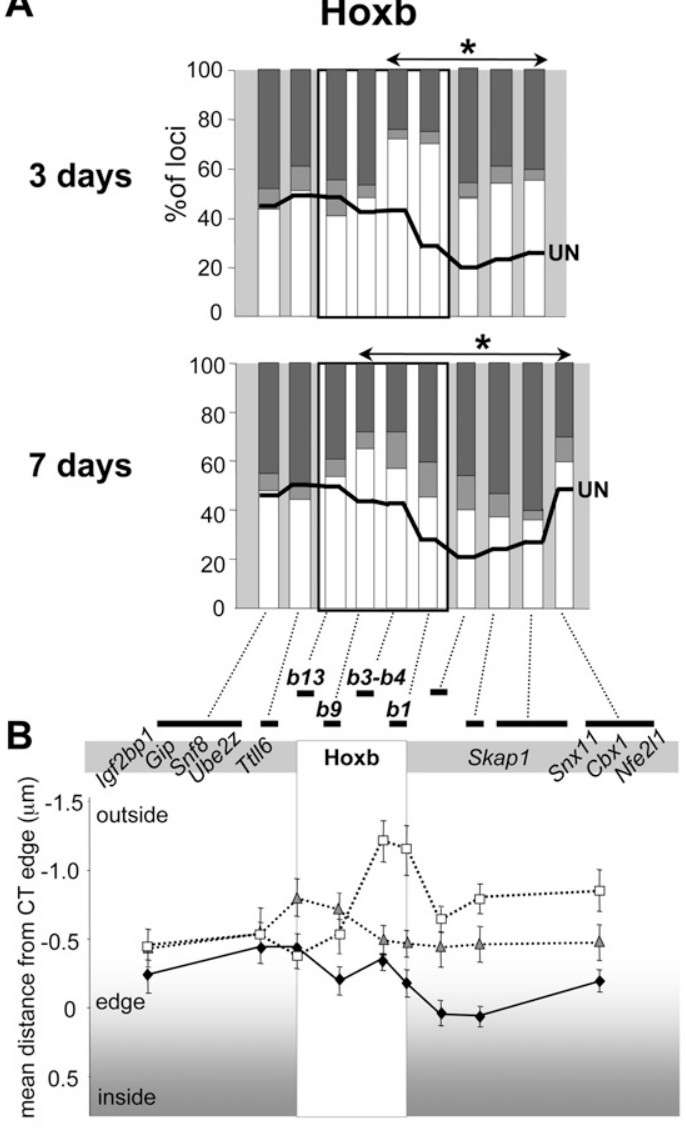

Hoxd

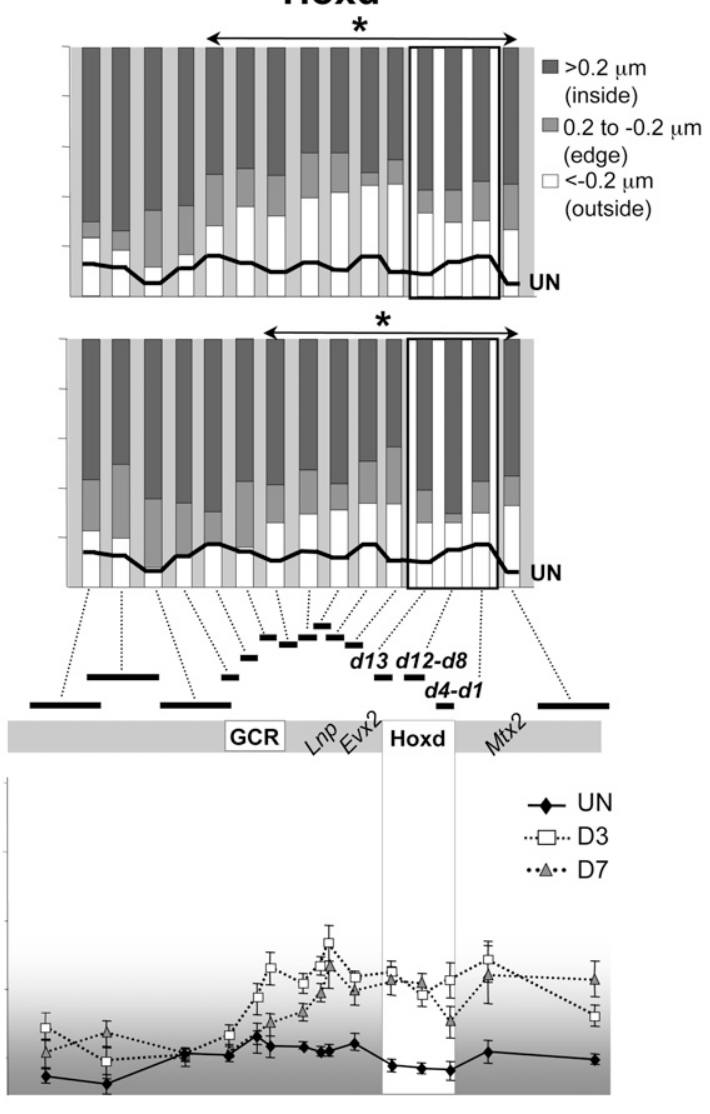

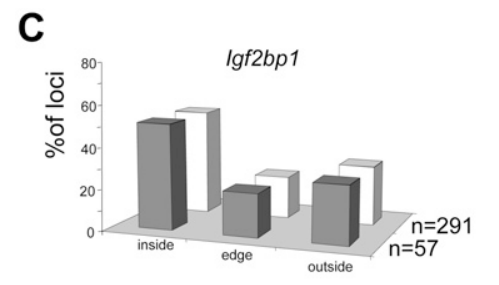
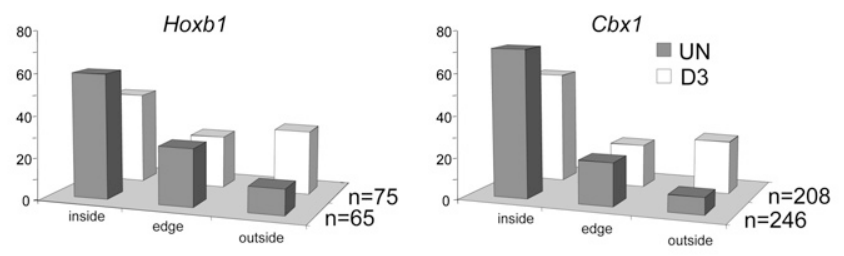

position relative to chromosome territory

Figure 3. Chromosome territory reorganization during ES cell differentiation. (A) Histograms showing the percentage of signals across the Hoxb or Hoxd regions located on either inside ( $>0.2 \mu \mathrm{m}$; dark gray bars), at the edge ( $\pm 0.2 \mu \mathrm{m}$; light gray bars), or outside $(<-0.2 \mu \mathrm{m}$ white bars) of the MMU11 $($ Hoxb) or the MMU2 CT $($ Hoxd), as measured by 2D FISH in OS25 ES cells differentiated for 3 or $7 \mathrm{~d}$. The thick black line shows the corresponding data in undifferentiated ES cells (from Fig. 2B). Probes showing a further significant $(P<0.05)$ relocalization toward the outside of the CT during differentiation are indicated by the asterisked regions $(n=100)$. (B) Mean position $(\mu \mathrm{m}) \pm$ SEM, measured by 2D FISH, of the Hoxb genomic region relative to the edge of MMU11 CT (left), or of the Hoxd genomic region relative to the edge of MMU2 CT (right) in undifferentiated OS25 ES cells (filled diamonds) and in cells differentiated for $3 \mathrm{~d}$ (open squares) or $7 \mathrm{~d}$ (shaded triangles). (C) Position of Hoxb1 and 5' (Ifg2bp1) or 3' (Cbx1) flanking regions relative to the MMU11 $\mathrm{CT}$ (inside of, edge, or outside of) assayed by 3D FISH in pFa fixed undifferentiated ES cells (filled bars), and cells differentiated for $3 \mathrm{~d}$ (open bars). 
(Fig. 4). Differentiation was apparent from the dramatically reduced steady-state levels of transcripts from three markers of pluripotency (Oct4, Sox2, and Nanog). mRNA levels of two constitutively expressed housekeeping genes, Rrm2 and Hprt1, remained constant. There was strong induction of Hoxb genes during differentiation (Fig. 4B), and this was supported by RT-PCR data (not shown). In contrast, there was no detectable induction of neighboring genes on either side of $H o x b$. Indeed, expression of Skap1, located immediately 3' of Hoxb1, appeared to be decreased upon differentiation as judged from the tiling array (this gene is not present on the expression array used), even though this gene is significantly relocalized further toward the outside of the CT during differentiation (Fig. 3). In comparison with Hoxb, Hoxd genes are only moderately up-regulated during differentiation. This might be linked to the differentiation pathways the cells have engaged in, or the different genomic contexts of the two Hox clusters.

We conclude that there is no bystander activation of flanking unrelated genes during Hox gene induction, and that the enhanced looping out from the CT during Hox activation does not, de facto, lead to the activation of otherwise silent genes, nor does it further enhance the transcription of already active genes.

\section{Hoxb and Hoxd are not colocalized in the nucleus}

What then is the functional significance of looping out for the Hox genes themselves? One possibility is that Hox loci are being relo- calized to a specific nuclear site to enable their coordinate regulation by shared regulatory complexes. There is conflicting data with regard to nuclear colocalization of Hox loci in Drosophila and whether this is related to their regulation by polycomb (PcG) complexes (Bantignies et al. 2003; Fedorova et al. 2008). Therefore, we analyzed the spatial proximity of Hoxb1 and Hoxd1 alleles in ES cells, before and after differentiation (Fig. 5A). Consistent with another study (Lanctot et al. 2007), we did not detect evidence for substantial colocalization, or close association, of Hox loci in trans, either in the silent (undifferentiated) or active (differentiated) state by 2D FISH (Fig. 5B). There was also no colocalization seen by 3D FISH of differentiated cells (Fig. 5C).

\section{Preferential CT organization of nonexpressing vs. expressing alleles}

To more directly address the relationship between gene expression and CT organization we determined the nuclear distribution of transcribing alleles using RNA-FISH with intron probes (Supplemental Table S3) followed by DNA-FISH with genomic probes. We were unable to visualize nascent RNA signals for Hoxb1 or Hoxd1, probably due to the short and single intron structure of their transcription units, thus ensuring rapid mRNA processing and export to the cytoplasm. Therefore, we analyzed the nuclear behavior of two constitutively expressed genes, Igf $2 b p 1$ and Cbx1, which flank Hoxb to the $5^{\prime}$ and $3^{\prime}$ sides, respectively (Fig. 1). $I g f 2 b p 1$ is in a region that is already substantially (35\% of alleles)
A

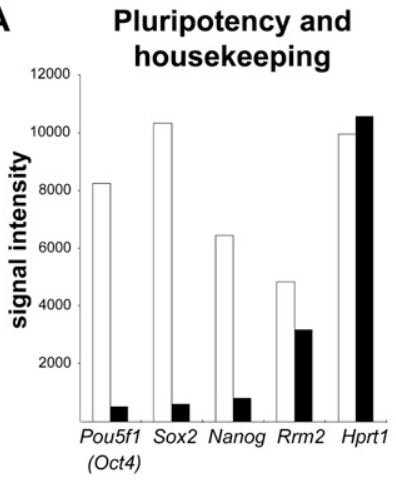

B

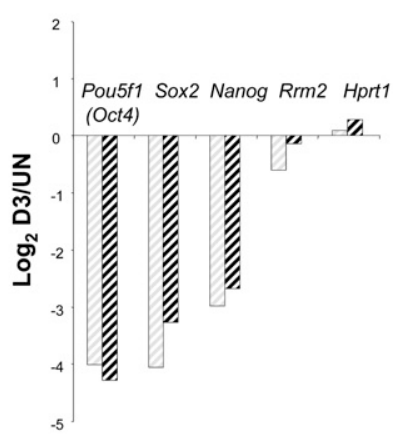

Hoxb
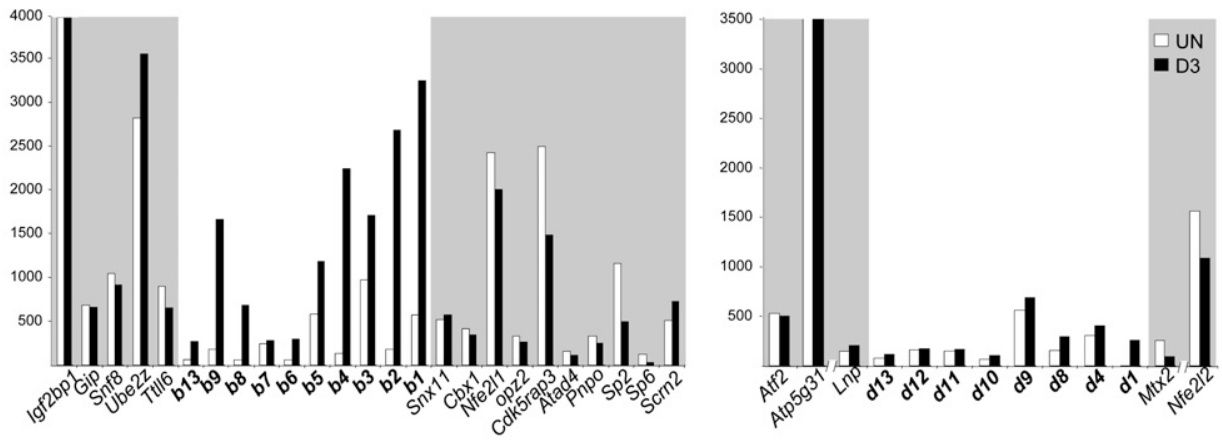

Figure 4. Gene expression around Hoxb and Hoxd during ES cell differentiation. (A) Signal intensities of cDNAs from undifferentiated ES cells (UN, white columns) or from cells differentiated for $3 \mathrm{~d}$ (D3, black columns) monitored using a CDNA microarray (GEO accession GSE15166). Results for pluripotency (Oct4, Sox2, Nanog) and housekeeping genes (Rrm2, Hprt1) (left), and the Hoxb (middle) or Hoxd (right) genomic regions are shown. (B) As in A, but showing the $\log _{2}$ ratio of D3/UN cDNA on a cDNA microarray (light hatched columns) or a Hoxb/Hoxd tiling microarray (dark hatched columns). Data are the mean of three independent experiments including a dye swap.

\section{Genome Research www.genome.org}




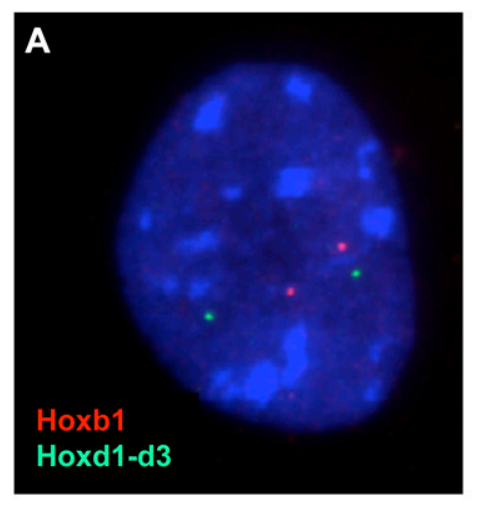

B

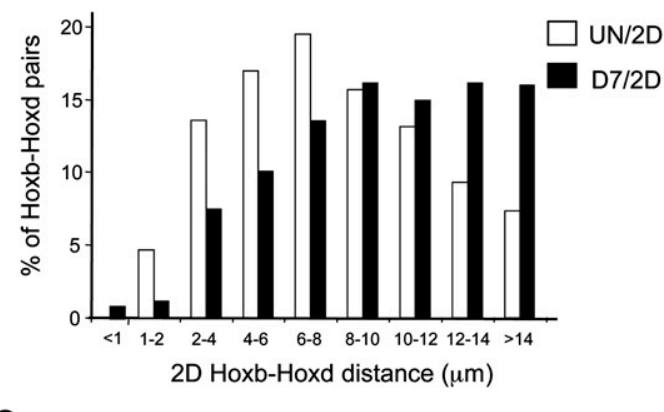

C

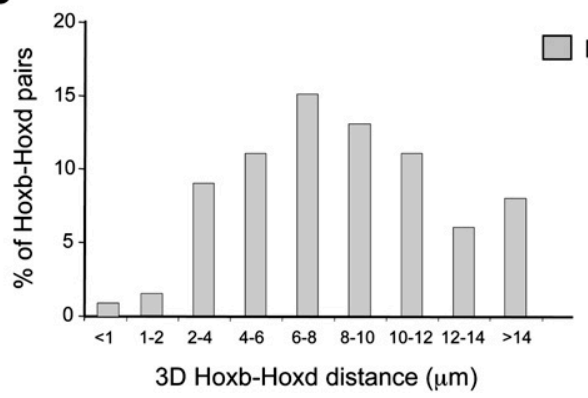

Figure 5. Spatial proximity between Hoxb1 and Hoxd1 loci. $(A)$ Three-color DNA-FISH on DAPI counterstained nucleus from a differentiated (7 d) OS25 ES cell using probe for Hoxb1 (BAC MMP-4; as in Chambeyron and Bickmore [2004]) in red, and fosmid probe for Hoxd1-d3 (WI1-121N10) in green. (B) Histogram showing the distribution of distances between the Hoxb and Hoxd signals measured by 2D FISH in nuclei from undifferentiated and differentiated $(7 \mathrm{~d})$ cells (59 and 87 nuclei analyzed, respectively). Distances are slightly larger in differentiated cells due to the increased nuclear volume. (C) As in $B$ but using 3D FISH on pFa fixed cells.

localized outside of the CT in undifferentiated cells and this is not further increased upon differentiation (Fig. 3C). In contrast, few (8\%) $C b x 1$ signals were seen outside of the CT in undifferentiated cells but localization to positions exterior of the CT is increased (to $>25 \%$ of alleles) during differentiation by the spread of CT reorganization emanating from Hoxb (Fig. 3C).

In agreement with microarray analysis, expression of $I g f 2 b p 1$ was more abundant ( $72 \%$ of cells showed an RNA-FISH signal) than that of $C b x 1(27 \%)$ and this did not significantly change during differentiation (Fig. 6A). We then used DNA-FISH, with a MMU11 chromosome paint and a corresponding BAC probe, to assess the relative CT organization of transcribing vs. nontranscribing alleles in these same cells. Analysis was confined to cells where RNA-FISH signal was detectable at at least one of the alleles. Of the nontranscribing (RNA-FISH signal negative) alleles, $>72 \%$ were located well inside of, and $<9 \%$ were scored as exterior to, the CT in undifferentiated cells (Fig. 6B). Since RNA-FISH is likely not $100 \%$ efficient and the BACs used for DNA-FISH also encompass other neighboring genes (Gip, Snf8, Ube2, and Atp5g1 for the Igf2bp1 BAC, and Snx11, Nfe2l1, and Copz2 for Cbx1 BAC), we cannot exclude that some of these latter signals are actually expressing alleles of these other genes.

The distribution of actively transcribing (RNA-FISH +ve) alleles was significantly different from that of the inactive ones $\left(P<0.0001\right.$ by $\left.\chi^{2}\right)$. Whereas, the nontranscribing alleles were preferentially located inside the CT, actively transcribing alleles were distributed between locations inside, at the edge, and outside of the CT (Fig. 6B). As the proportion of $C b x 1$ alleles exterior to the $\mathrm{CT}$ increased during differentiation, there was no significant change in the intra-CT distribution of the nontranscribing alleles $(P>0.05)$. Therefore, it is the already active alleles that seem to be the ones that can relocate more to the outside of the CT during differentiation $(P=0.003)$.

\section{Looping out of Hoxbl, but not of flanking genes, coincides with colocalization with transcription factories}

Nuclear movements are thought to allow for, or to be a consequence of, recruitment of genes to specialized nuclear compartments. Actively transcribing genes have been reported to associate with foci of RNA polymerase II (RNAPII) - termed transcription factories (Osborne et al. 2004). Using immuno-DNA-FISH with an antibody (H5) specific for the Ser2 phosphorylated (elongating) form of RNAPII (RNAPIIo), we analyzed the association of Igf $2 b p 1, C b \times 1$, and Hoxb1 genomic regions with these foci (Fig. 7A). We quantified the proportion of DNAFISH signals colocalized with, or distinct from, the foci of RNAPIIo (Fig. 7B). Approximately $30 \%$ of $C b x 1$ BAC signals colocalized with RNAPIIo foci, similar to the percentage of actively transcribed $C b \times 1$ alleles detected in RNA-FISH. For the BAC encompassing Igf $2 b p 1$ and neighboring genes, the percentage of colocalized loci (48\%) in undifferentiated cells was lower than the proportion of Igf $2 b p 1$ alleles with RNA-FISH signals and we do not know the reason for this. In stark contrast, there was no colocalization between Hoxb1 alleles and RNAPIIo foci in undifferentiated cells where this Hoxb1 is silent, but in differentiated cells $35 \%$ of alleles could now be seen to be colocalized. These data provide further support to the idea that much gene transcription takes place in association with transcription factories containing hyperphosphorylated RNAPII (Kimura et al. 2002; Osborne et al. 2004).

By comparing the spatial organization of RNAPIIo-colocalized and noncolocalized alleles, we then asked where this recruitment to RNAPII foci occurs in relation to CTs (Fig. 7C). Consistent with the RNA-FISH data (Fig. 6), Cbx1 and Igf2bp1 loci colocalized with RNAPIIo inside, at the edge, or outside of the CT. However, both before and after differentiation, there was a preferential distribution of the colocalized alleles away from the CT interior and toward the CT edge and exterior compared to the noncolocalized alleles $\left(P<0.001\right.$ in $\chi^{2}$ test). For Hoxb1, there was also a preference for the associated alleles to be excluded from the interior of the CT $(P<0.001)$.

To analyze directly the association of a single transcribing gene with transcription factories, we performed RNAimmuno-FISH using intronic probes for either $I g f 2 b p 1$ or $C b x 1$ on cells grown on slides, using mild conditions of fixation and permeabilization in order to preserve the nuclear architecture (Fig. 8). Greater than $60 \%$ of transcribing (RNA-FISH positive) alleles of Igf $2 b p 1$ and $C b x 1$ completely colocalized with visible foci of 
A
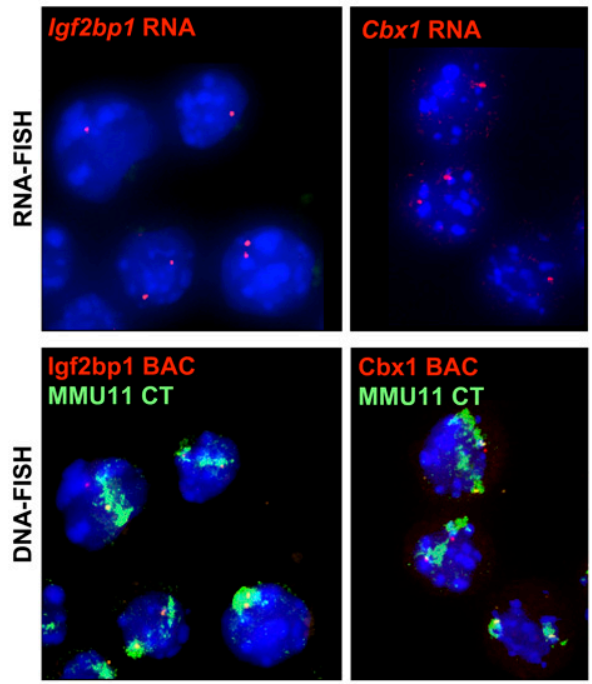

B

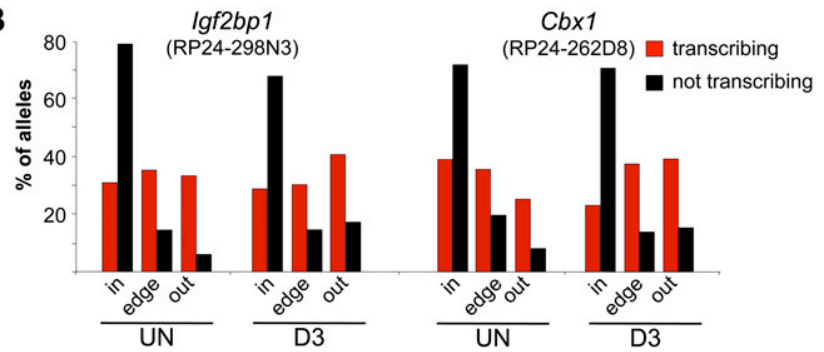

Figure 6. Nuclear organization of actively transcribing alleles. (A) (Top panels) RNA-FISH with lgf $2 b p 1$ or $C b x 1$ intronic probes (red) on DAPI counterstained nuclei of cytospun OS25 ES cells. (Lower panels) Same nuclei after denaturation and DNA-FISH with BAC probes overlapping lgf2bp1 (RP24-298N3) and Cbx1 (RP24-262D8) regions (red) together with an MMU11 chromosome paint (green). (B) Histogram showing the percent of actively transcribing/ RNA-FISH +ve (red) or nontranscribing (black) Igf2bp1 or $C b x 1$ alleles located inside (in), at the edge (edge), or outside (out) of the MMU11 CT in undifferentiated (UN) OS25 ES cells and in cells differentiated for $3 \mathrm{~d}$ (D3). Analysis was confined to cells with at least one RNA-FISH signal. For Igf2bp1 $n=288$ and 192, UN and D3, respectively. For $C b x 1, n=320$ (UN) and 128 (D3).

RNAPIIo and $<32 \%$ of RNA-FISH negative alleles were colocalized. To analyze the intra-CT position of active and inactive loci, we then denatured the nuclei and cohybridized them with a MMU11 paint and a BAC probe corresponding to either $C b x 1$ or $I g f 2 b p 1$. As expected from our previous data, we detected a differential intraCT localization whether comparing either the RNA-FISH positive vs. negative alleles, or the RNAPIIo colocalized vs. noncolocalized alleles.

\section{Discussion}

\section{Bystander gene activation}

The clustering of genes in the genome sequence means that nuclear reorganization at one locus will inevitably influence the spatial organization of neighboring genes. If nuclear reorganization is a directed mechanism for the regulation of gene expression, then genes might be activated just because of their proximity to genes that are subject to nuclear reorganization. There are documented examples of bystander effects on gene ex- pression (Cajiao et al. 2004; Ebisuya et al. 2008) but nothing is known about nuclear organization in these cases.

Recently, the integration of the beta-globin LCR into a region of the mouse genome containing a high density of genes with widespread and diverse expression patterns, was shown to increase the expression of some of these flanking genes in the embryonic liver-where the endogenous beta-globin locus is active (Noordermeer et al. 2008). The integrated LCR also induced both an increased localization of the region to the edge, and to the outside, of the CT, and a slightly increased association with foci of RNAPIIo. Therefore in this case, there was a bystander

A
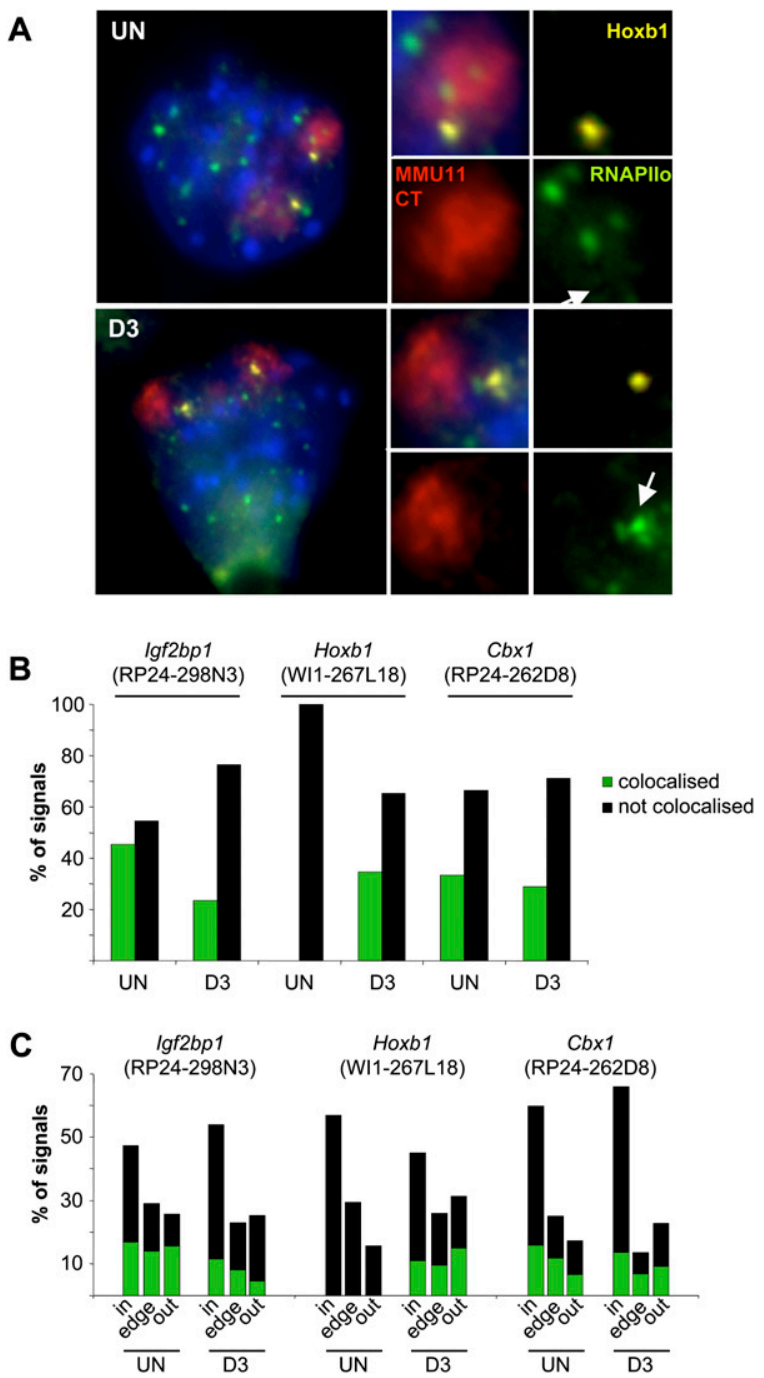

Figure 7. Locus colocalization with foci of RNAPII. (A) Immuno-FISH using an antibody against the phosphorylated form of RNAPII (green), Hoxb1 probe WI1-267L18 (yellow), and MMU11 chromosome paint (red) in undifferentiated ES cells (UN) or cells differentiated for $3 \mathrm{~d}$ (D3). The insets to the right show magnified images from one CT with arrows indicating the position of the Hoxb1 locus in the RNAPIlo channel. (B) Histogram showing the percent of signals either colocalized with (dark green) or distinct from (not colocalized; black) phosphorylated RNAPII foci for the regions encompassing lgf2bp1 (BAC RP24-298N3), Hoxb1 (fosmid WI1-267L18) or Cbx1 (BAC RP24-262D8) in undifferentiated (UN) or differentiated cells (D3). (C) Histogram of the nuclear distribution of signals in $A$ with respect to their CT edge. $n=341$ (Un), 89 (D3) for lgf2bp1; 62 (Un), 73 (D3) for Hoxb1; and 200 (Un), 90 (D3) for Cbx1. 
A

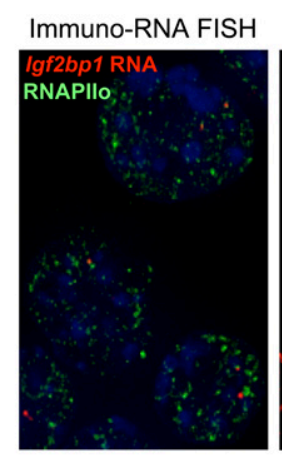

DNA-FISH

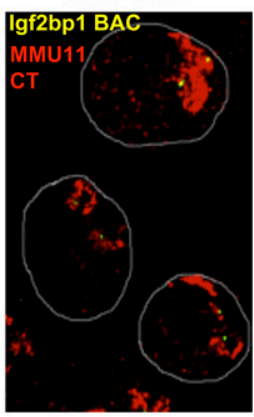

B

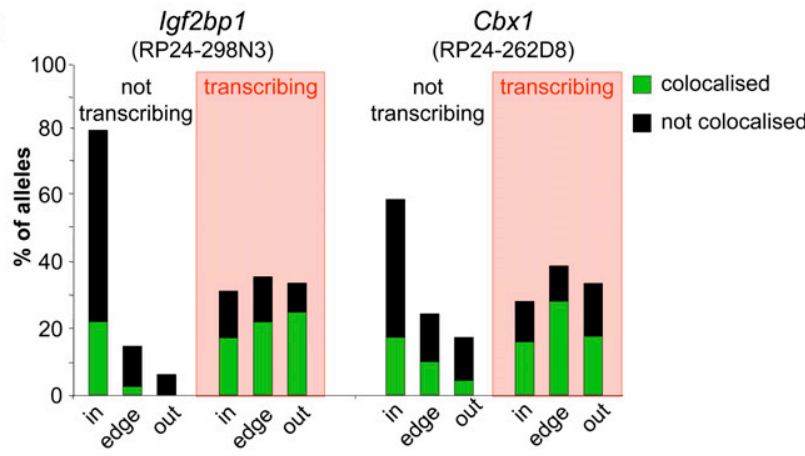

Figure 8. Active vs. inactive allele colocalization with foci of RNAPII. $(A)$ Maximal projection image after deconvolution of 3D RNA-immuno-FISH using an lgf $2 b p 1$ intronic probe (red) and an antibody against the phosphorylated form of RNAPII (green) on DAPI counterstained nuclei of undifferentiated OS25 cells (left panel). The DAPI channel has been attenuated in order to improve the visualization of red and green signals. The right panel shows the same nuclei after denaturation and DNA-FISH with a BAC probe encompassing Igf2bp1 (RP24-298N3, yellow) together with an MMU11 chromosome paint (red). (B) Histogram showing the percent of nontranscribing and transcribing (shaded in red) Igf2bp 1 or $C b \times 1$ alleles located inside (in), at the edge (edge), or outside (out) of the MMU11 CT together with the percent of alleles colocalized with (green) or distinct from (not associated, black) a phosphorylated RNAPII focus within each category in undifferentiated OS 25 cells. $n=288$ (not transcribing), 206 (transcribing) for Igf $2 b p 1$ and 128 (not transcribing), and 57 (transcribing) for $C b \times 1$.

effect on both gene expression and CT organization induced by the LCR.

Here we show that there is also a bystander effect on the nuclear organization of genes flanking the 3 ' side of Hoxb. They increase their localization to the outside of the CT during differentiation, as a consequence of Hoxb activation and reorganization (Fig. 3). However, there is no accompanying change in their expression (Fig. 4).

It was already known that localization outside of CTs is not sufficient to activate genes from an inactive state, but this could be attributed to lack of appropriate transcription factors (Mahy et al. 2002; Brown et al. 2006). In our study here, the Hoxb flanking genes are already active, but we do not observe any further increase in their expression as a result of further CT looping out. This is consistent with the conclusion of Noordermeer et al. (2008), which is that looping out is a by-product of LCR activity and that the bystander gene activation is due to direct contacts between this strong regulatory element and flanking genes. There is no known long-range regulatory element needed for Hoxb activation during ES cell differentiation.
Preferential localization of inactive alleles inside of chromosome territories

Even though we show that localization of Hox flanking genes further to the outside of CTs is not sufficient to increase their expression, we do observe a correlation between gene activity and CT organization. Using combined RNA- and DNA-FISH, we show that inactive and active alleles have a significantly different distribution within the CT from each other. Although actively transcribing alleles, as defined by the presence of a corresponding RNA-FISH signal, are found at positions inside, at the edge, and outside of the CT, inactive alleles are preferentially retained inside of the CT (Fig. 6).

Actively transcribing genes have been shown to have a preferential association with transcription factories-visibly detectable concentrations of phosphorylated RNAPII that are coincident with sites of BrUTP incorporation (Osborne et al. 2004; Brown et al. 2008). We found that the alleles of Hoxb flanking genes that colocalized with RNAPIIo foci were differentially localized in the CT compared to the nonassociated alleles (Fig. 7). The latter are preferentially found in the CT interior, whereas RNAPIIo colocalized alleles are distributed between positions inside, at the edge, and outside of the CT. As the frequency of alleles found outside of the CT increased during differentiation, there was no further increase in transcription factory association, consistent with the absence of increased gene expression. However, it was the alleles already associated with transcription factories, and therefore considered transcriptionally active, that seemed to be the ones that preferentially are able to be repositioned in the nucleus. Noordermeer et al. (2008) concluded that the increased transcription factory association, induced by the beta-globin LCR, occurred independent of position within the CT. However, in that study the frequency of alleles scored well inside of the CT, was too low to exclude that there may be a deficiency of factory-associated alleles in the CT interior.

Our data are consistent with previous observations of sites of BrUTP incorporation (Abranches et al. 1998; Verschure et al. 1999) or RNAPIIo concentration (Branco and Pombo 2006) within CTs. Together these data suggest that genes in the "mundane" genomic regions that flank Hox loci, and perhaps most genes in the genome, are transcribed in association with transcription factories (Osborne et al. 2004) that are not restricted to sites at the edge or outside of the CT. Our data do not distinguish whether genes move to preexisting factories upon activation, or whether factories might be assembled de novo upon activated genes.

We have shown here that Hox gene activation during the differentiation of ES cells, correlates with the association of Hox loci with transcription factories marked by RNAPII phosphorylated on Ser 2 of the CTD. This is considered to be the actively elongating form of polymerase. The recent identification of forms of RNAPII phosphorylated on Ser5 at genes, including Hox, silenced by polycomb in ES cells (Stock et al. 2007), raises the possibility that in undifferentiated ES cells Hox loci may be associated with foci containing this form of RNAPII.

\section{Altered chromatin mobility may explain the link between the ability to locate outside of CTs and transcription}

We conclude that it is not looping out from the CT per se, but rather the ability of a genome region to be seen as looped out from the CT, that is important for active transcription. Looping out from the CT is therefore likely to be a manifestation of some other underlying change in chromatin structure that enhances 
chromatin mobility (Fraser and Bickmore 2007). This might then allow genes the freedom to explore a larger proportion of the nuclear space, both inside and outside of the CT, and hence increases the probability that a gene will be able to engage with a transcription factory. In this model, it is the restraint on chromatin motion, for alleles that are not able to move outside of CTs, that restricts their ability to be transcribed and not their intra-CT position per se. This then raises the challenge of identifying the chromatin structures that modulate chromatin mobility.

\section{Methods}

\section{ES cell culture and differentiation}

OS25 ES cells were cultured as previously described (Chambeyron and Bickmore 2004; Morey et al. 2007). Differentiation was induced by plating the cells at low density without LIF or hygromycin for $1 \mathrm{~d}$. Retinoic acid (RA), $5 \times 10^{-6} \mathrm{M}$, was then added. RNA samples were collected and nuclei were prepared after 3 or $7 \mathrm{~d}$ of differentiation (respectively, $2 \mathrm{~d}$ of RA treatment and $4 \mathrm{~d}$ with and $2 \mathrm{~d}$ without RA). Similar FISH results were obtained on samples collected from two independent differentiation experiments. FISH data presented in this paper all come from the same differentiation.

\section{Multicolor DNA fluorescence in situ hybridization}

For 2D FISH, nuclei were isolated in $0.56 \% \mathrm{KCl}$ and fixed with $3: 1 \mathrm{v} / \mathrm{v}$ methanol/acetic acid (Chambeyron and Bickmore 2004). For 3D FISH, nuclei were fixed with $4 \%$ paraformaldehyde $(\mathrm{pFa})$. FITC-labeled paint for MMU2 or MMU11 were purchased from CAMBIO. BAC and fosmid clones covering the Hoxb and Hoxd regions were chosen from Ensembl v37, February 2006 (http:// www.ensembl.org/Mus_musculus/index.html). BAC clones were purchased from BACPAC resources center and fosmid clones were kindly provided by the Sanger Institute (for coordinates and names, see Supplemental Table S1). DNA from these clones were prepared using standard alkaline lysis and labeled with digoxigenin-11-dUTP or with biotin-16-dUTP (Roche) by nick translation. Approximately $200 \mathrm{ng}$ of FITC-paint, $100 \mathrm{ng}$ of biotinlabeled BAC/fosmid probe, and $100 \mathrm{ng}$ of digoxigenin $\mathrm{BAC} /$ fosmid probe were used per slide, together with $15 \mu \mathrm{g}$ of mouse Cot- 1 DNA (GIBCO BRL) and $5 \mu \mathrm{g}$ salmon sperm DNA. Digoxigenin-labeled probes were detected using Rhodamine anti-digoxigenin and Texas red anti-sheep IgG (Vector Laboratories); biotin-labeled probes were detected using Cy5 streptavidin and biotinylated antiavidin (Vector Laboratories) and the FITC signal from the MMU2 or MMU11 chromosome paint was amplified using F1 rabbit antiFITC and F2 FITC anti-rabbit (CAMBIO). Hybridization, washes, detection, and imaging were as described (Chambeyron and Bickmore 2004). Slides were mounted in Vectashield (Vector) and counterstained with $0.5 \mu \mathrm{g} / \mathrm{mL}$ DAPI.

\section{RNA-FISH}

Probes for RNA-FISH consisted of a mix of PCR products from the introns of $I g f 2 b p 1$ or $C b x 1$ and were labeled using nick translation. Primer sequences are shown in Supplemental Table S3. The RNAFISH procedure was as previously described (Debrand et al. 1999). Briefly, cells were cytospun onto SUPERFROST glass slides (4 min, $350 \mathrm{rpm}$, Shandon Cytospin), permeabilized with 0.5\% Triton $\mathrm{X}$-100 in ice-cold cytoskeletal buffer complemented with $2 \mathrm{mM}$ Vanadyl Ribonucleoside Complex (VRC) (New England Biolabs) for $7 \mathrm{~min}$, fixed with $4 \% \mathrm{pFa}$ on ice for $10 \mathrm{~min}$ and stored in $70 \%$ ethanol at $4^{\circ} \mathrm{C}$. Slides were then dehydrated and hybridized di- rectly. One microliter of RNase inhibitor (Invitrogen) was added to the hybridization mix. Hybridization conditions were the same as for DNA-FISH. Slides were washed in $50 \%$ formamide $2 \times$ SSC $(\mathrm{pH} 7.5)$ at room temperature, then at $37^{\circ} \mathrm{C}$ and then in $2 \times \mathrm{SSC}$ at room temperature. Signal detection was as for DNA-FISH. A control with treatment with RNase confirmed signal specificity. A minimum of $502 \mathrm{D}$ images comprising at least one nucleus with an RNA-FISH signal were captured and the slide coordinates recorded. Standard DNA-FISH was then applied and the same cells relocated on the slide.

\section{Immuno-FISH}

Immunofluorescence followed by DNA-FISH was as described at http://www.epigenome-noe.net/researchtools/protocol.php?protid= 3 (Chaumeil et al. 2004). Cells grown on slides were fixed with $4 \%$ $\mathrm{pFa}(\mathrm{pH} 7.4)$ for $15 \mathrm{~min}$ at room temperature, washed twice in icecold PBS, and stored at $4^{\circ} \mathrm{C}$ in PBS. Before immunostaining, cells were permeabilized with $0.5 \%$ Triton X-100/PBS for $12 \mathrm{~min}$ at room temperature. Cells were then incubated with the anti-RNAPII H5 $(1 / 100$, Covance) and detected with a fluorescein anti-mouse $(1 / 100$, Vector Laboratories) secondary antibody. Slides were post-fixed with $3 \%$ formaldehyde for $10 \mathrm{~min}$ at room temperature, incubated in 0.1 $\mathrm{M} \mathrm{HCl}$ for $10 \mathrm{~min}$ at room temperature, denatured for $30 \mathrm{~min}$ at $80^{\circ} \mathrm{C}$ in $50 \%$ formamide $2 \times$ SSC ( $\mathrm{pH} 7.5$ ), and hybridized.

\section{RNA-immuno-FISH/DNA-FISH}

Cells grown on slides were fixed with $3 \% \mathrm{pFA}(\mathrm{pH}$ 7.4) for $10 \mathrm{~min}$ on ice, permeabilized with $0.5 \%$ Triton X-100/PBS complemented with $2 \mathrm{mM}$ VRC for $5 \mathrm{~min}$ on ice, washed once in $2 \times$ SSC, hybridized overnight, and washed as described above. Slides were post-fixed with $3 \% \mathrm{pFa}$ for $10 \mathrm{~min}$ at room temperature and repermeabilized with $0.5 \%$ Triton X-100/PBS complemented with $2 \mathrm{mM}$ VRC for $5 \mathrm{~min}$ on ice. Immunostaining procedure was as described above. One-one hundreths of RNase inhibitor was added to blocking buffers and primary and secondary antibodies. Three-dimensional images of nuclei with at least one RNA-FISH signal were captured and the coordinates of these cells recorded before DNA-FISH.

\section{Image capture and analysis}

Two-dimensional slides were examined using a Zeiss Axioplan II fluorescence microscope with Plan-neofluar objectives, a $100 \mathrm{~W}$ Hg source (Carl Zeiss) and Chroma \#84000 quadruple band pass filter set (Chroma Technology Corp.) with the excitation filters installed in a motorized filter wheel (Ludl Electronic Products). Grayscale images were captured with a Hamamatsu Orca AG CCD camera (Hamamatsu Photonics Ltd.). Image capture and analysis were performed using in-house scripts written for IPLab Spectrum (Scanalytics Corp.). The distance between two probes, and probe position relative to the CT edge, were calculated as described (Chambeyron and Bickmore 2004; Chambeyron et al. 2005; Morey et al. 2007). In this analysis a probe signal is considered to be outside of the CT when its distance to the CT edge is negative. Conversely, distances $>0$ correspond to probe signals inside of the CT.

Three-dimensional images were captured on a Zeiss Axioplan II fluorescence microscope with the objective fitted with a Pifoc motor. Single plane images were deconvolved using the iterative restoration (20 iterations) from Volocity (Improvision) software.

\section{Statistical analysis}

The statistical relevance of DNA-FISH CT position data was assessed using the nonparametric Kolmogorov-Smirnov test to 
examine the null hypothesis that two sets of data show the same distribution. The data sets consisted of at least 50 nuclei (100 territories/loci) for each differentiation time and for each combinatory of probes. A $P$-value $<0.05$ was considered statistically significant.

The statistical significance of RNA/DNA-FISH and immunoDNA-FISH data was assessed by $\chi^{2}$.

\section{Microarray design and hybridization}

The mouse cDNA oligonucleotide microarray represented 38,000 mouse genes from the Mouse Exonic Evidence Based Oligonucleotide set (van den Ijssel et al. 2005) (GEO accession: GPL4468). For the custom tiling array, 60-mer oligos (Invitrogen/Illumina) were designed alternatively on each strand of mouse chromosome 2 and 11 to cover Hoxd and Hoxb core regions, proximal flanking regions, and distal flaking regions (one oligo every 250, 500, and $50 \mathrm{~kb}$, respectively). Additional oligos were designed on exons of genes of interest: Hoxb, Hoxd, flanking genes, differentiationrelated genes, and housekeeping genes (Supplemental Table S2). Amine-modified oligos were spotted at $20 \mu \mathrm{M}$ in $1 \times$ Nexterion Spot buffer containing $0.005 \%$ Triton X100 onto Codelink activated slides by the University of Liverpool Microarray Facility.

Total RNA was extracted from OS25 cells with TriReagent (Sigma). Ten micrograms of RNA were reverse-transcribed using SuperScript Direct cDNA labeling kit (Invitrogen) to produce oligodT primed cDNAs labeled with Cy3 or Cy5-dCTP (Amersham). cDNAs were purified with a Qiagen PCR purification kit and quantified with a Nanodrop ND-1000 spectrophotometer. Equivalent amounts of cDNAs $(1-2 \mu \mathrm{g}$ cDNA corresponding to about $100 \mathrm{pmol}$ of incorporated dye) from undifferentiated and differentiated cells labeled with a different dye were precipitated together with $10 \mu \mathrm{g}$ of salmon sperm DNA, $500 \mu \mathrm{g}$ of yeast tRNA and resuspended in $45 \mu \mathrm{L}$ of hybridization buffer $(50 \%$ deionized formamide, $5 \times$ SSC, $5 \times$ Denhardt, $0.1 \%$ SDS). This hybridization mix was denaturated for $8 \mathrm{~min}$ at $94^{\circ} \mathrm{C}$ and pipetted onto the prewarmed microarray slide. Hybridization was overnight under a $22 \times 64 \mathrm{~mm}$ coverslip in a humid chamber floating in a $42^{\circ} \mathrm{C}$ water bath. Slides were washed with gentle shaking as follows: $2 \times$ $5 \mathrm{~min}$ in $2 \times \mathrm{SSC}, 0.1 \% \mathrm{SDS}$ at $42^{\circ} \mathrm{C} ; 2 \times 5 \mathrm{~min}$ in $0.2 \times \mathrm{SSC}$ at room temperature; $2 \times 5 \mathrm{~min}$ in $0.1 \times \mathrm{SSC}$ at room temperature; and $30 \mathrm{~s}$ in $0.01 \times$ SSC at room temperature. Slides were dried by centrifugation at $1000 \mathrm{rpm}, 5 \mathrm{~min}$ at room temperature.

Slides were scanned using Genepix (Axon Instruments). Analysis was done with BlueFuse software (Cambridge BlueGnome). Normalization between the two channels (i.e., undifferentiated/differentiated cells cDNAs) was by global Lowess for the cDNA library microarrays, and by global median based on housekeeping genes for the Hox tiling arrays. For the tiling arrays there were two biological and one technical (dye-swap) replicates, and for the expression arrays there were two replicates. These were normalized to each other by a Lowess normalization.

\section{Acknowledgments}

C.M. was an EMBO long-term fellow and then was a recipient of a Marie Curie Intra European Fellowship (MEIF-CT-2006-021308); C.K. was supported by the EU FP6 Network of Excellence Epigenome (LSHG-CT-2004-503433); W.A.B. is a Centennial Fellow of the James S. McDonnell foundation. We thank Bauke Ylstra (Micro Array Facility, VUMC Cancer Center Amsterdam) for the mouse expression arrays, Nick Gilbert (University of Edinburgh Cancer Research Centre) for help with Hox tiling microarray design, Margaret Hughes (Liverpool Microarray Facility) for microarray slide printing, and James Prendergast (MRC HGU) for Lowess normalization of data.

\section{References}

Abranches R, Beven AF, Ragon-Alcaide L, Shaw PJ. 1998. Transcription sites are not correlated with chromosome territories in wheat nuclei. J Cell Biol 143: 5-12.

Bantignies F, Grimaud C, Lavrov S, Gabut M, Cavalli G. 2003. Inheritance of Polycomb-dependent chromosomal interactions in Drosophila. Genes \& Dev 17: 2406-2420.

Branco MR, Pombo A. 2006. Intermingling of chromosome territories in interphase suggests role in translocations and transcription-dependent associations. PLoS Biol 4: e138. doi: 10.1371/journal.pbio.0040138.

Brown JM, Leach J, Reittie JE, Atzberger A, Lee-Prudhoe J, Wood WG, Higgs DR, Iborra FJ, Buckle VJ. 2006. Coregulated human globin genes are frequently in spatial proximity when active. J Cell Biol 172: 177187.

Brown JM, Green J, das Neves RP, Wallace HA, Smith AJ, Hughes J, Gray N, Taylor S, Wood WG, Higgs DR, et al. 2008. Association between active genes occurs at nuclear speckles and is modulated by chromatin environment. J Cell Biol 182: 1083-1097.

Cajiao I, Zhang A, Yoo EJ, Cooke NE, Liebhaber SA. 2004. Bystander gene activation by a locus control region. EMBO J 23: 3854-3863.

Caron H, van Schaik B, van der Mee M, Baas F, Riggins G, van Sluis P, Hermus MC, van Asperen R, Boon K, Voute PA, et al. 2001. The human transcriptome map: Clustering of highly expressed genes in chromosomal domains. Science 291: 1289-1292.

Chambeyron S, Bickmore WA. 2004. Chromatin decondensation and nuclear reorganization of the HoxB locus upon induction of transcription. Genes \& Dev 18: 1119-1130.

Chambeyron S, Da Silva NR, Lawson KA, Bickmore WA. 2005. Nuclear reorganisation of the Hoxb complex during mouse embryonic development. Development 132: 2215-2223.

Chaumeil J, Okamoto I, Heard E. 2004. X chromosome inactivation in mouse embryonic stem cells: Analysis of histone modifications and transcriptional activity using immunofluorescence and FISH. Methods Enzymol 376: 405-419.

Debrand E, Chureau C, Arnaud D, Avner P, Heard E. 1999. Functional analysis of the DXPas34 locus, a 3' regulator of Xist expression. Mol Cell Biol 19: 8513-8525.

Ebisuya M, Yamamoto T, Nakajima M, Nishida E. 2008. Ripples from neighbouring transcription. Nat Cell Biol 10: 1106-1113.

Fedorova E, Sadoni N, Dahlsveen IK, Koch J, Kremmer E, Eick D, Paro R, Zink D. 2008. The nuclear organization of Polycomb/Trithorax group response elements in larval tissues of Drosophila melanogaster. Chromosome Res 16: 649-673.

Ferrier DE, Minguillon C. 2003. Evolution of the Hox/ParaHox gene clusters. Int J Dev Biol 47: 605-611.

Fraser P, Bickmore W. 2007. Nuclear organization of the genome and the potential for gene regulation. Nature 447: 413-417.

Gierman, HJ, Indemans MH, Koster J, Goetze S, Seppen J, Geerts D, van Driel R, Versteeg R. 2007. Domain-wide regulation of gene expression in the human genome. Genome Res 17: 1286-1295.

Kimura H, Sugaya K, Cook PR. 2002. The transcription cycle of RNA polymerase II in living cells. J Cell Biol 159: 777-782.

Lanctot C, Kaspar C, Cremer T. 2007. Positioning of the mouse Hox gene clusters in the nuclei of developing embryos and differentiating embryoid bodies. Exp Cell Res 313: 1449-1459.

Lercher MJ, Urrutia AO, Hurst LD. 2002. Clustering of housekeeping genes provides a unified model of gene order in the human genome. Nat Genet 31: $180-183$.

Mahy NL, Perry PE, Bickmore WA. 2002. Gene density and transcription influence the localization of chromatin outside of chromosome territories detectable by FISH. J Cell Biol 159: 753-763.

Morey C, Da Silva NR, Perry P, Bickmore WA. 2007. Nuclear reorganisation and chromatin decondensation are conserved, but distinct, mechanisms linked to Hox gene activation. Development 134: 909919.

Morey C, Da Silva NR, Kmita M, Duboule D, Bickmore WA. 2008. Ectopic nuclear reorganisation driven by a Hoxb1 transgene transposed into Hoxd. J Cell Sci 121: 571-577.

Noordermeer, D, Branco MR, Splinter E, Klous P, van IJcken W, Swagemakers S, Koutsourakis M, van der Spek P, Pombo A, de Laat W. 2008. Transcription and chromatin organization of a housekeeping gene cluster containing an integrated beta-globin locus control region. PLoS Genet 4: e1000016. doi: 10.1371/journal.pgen.1000016.

Osborne CS, Chakalova L, Brown KE, Carter D, Horton A, Debrand E, Goyenechea B, Mitchell JA, Lopes S, Reik W, et al. 2004. Active genes 
dynamically colocalize to shared sites of ongoing transcription. Nat Genet 36: 1065-1071.

Shopland LS, Johnson CV, Byron M, McNeil J, Lawrence JB. 2003. Clustering of multiple specific genes and gene-rich R-bands around SC35 domains: Evidence for local euchromatic neighborhoods. J Cell Biol 162: 981-990.

Shopland LS, Lynch CR, Peterson KA, Thornton K, Kepper N, Hase J, Stein S, Vincent S, Molloy KR, Kreth G, et al. 2006. Folding and organization of a contiguous chromosome region according to the gene distribution pattern in primary genomic sequence. J Cell Biol 174: 27-38.

Simonis M, Klous P Splinter E, Moshkin Y, Willemsen R, de Wit E, van Steensel B, de Laat W. 2006. Nuclear organization of active and inactive chromatin domains uncovered by chromosome conformation captureon-chip (4C). Nat Genet 38: 1348-1354.

Singer GA, Lloyd AT, Huminiecki LB, Wolfe KH. 2005. Clusters of coexpressed genes in mammalian genomes are conserved by natural selection. Mol Biol Evol 22: 767-775.

Sproul D, Gilbert N, Bickmore WA. 2005. The role of chromatin structure in regulating the expression of clustered genes. Nat Rev Genet 6: 775781.

Stock JK, Giadrossi S, Casanova M, Brookes E, Vidal M, Koseki H, Brockdorff N, Fisher AG, Pombo A. 2007. Ring1-mediated ubiquitination of H2A restrains poised RNA polymerase II at bivalent genes in mouse ES cells. Nat Cell Biol 9: 1428-1435.

van den Ijssel, P, Tijssen M, Chin SF, Eijk P, Carvalho B, Hopmans E, Holstege H, Bangarusamy DK, Jonkers J, Meijer GA, et al. 2005. Human and mouse oligonucleotide-based array CGH. Nucleic Acids Res 33: e192. doi: 10.1093/nar/gni191.

Verschure, P.J., van der Kraan I, Manders EM, van Driel R. 1999. Spatial relationship between transcription sites and chromosome territories. I Cell Biol 147: 13-24.

Volpi EV, Chevret E, Jones T, Vatcheva R, Williamson J, Beck S, Campbell RD, Goldsworthy M, Powis SH, Ragoussis J, et al. 2000. Large-scale chromatin organization of the major histocompatibility complex and other regions of human chromosome 6 and its response to interferon in interphase nuclei. J Cell Sci 113: $1565-1576$.

Williams RR, Broad S, Sheer D, Ragoussis J. 2002. Subchromosomal positioning of the epidermal differentiation complex (EDC) in keratinocyte and lymphoblast interphase nuclei. Exp Cell Res 272: 163175 .

Received November 9, 2008; accepted in revised form March 19, 2009. 


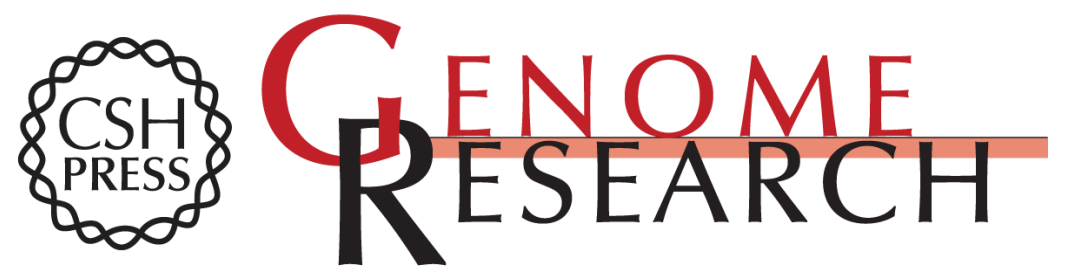

\section{Lack of bystander activation shows that localization exterior to chromosome territories is not sufficient to up-regulate gene expression}

Céline Morey, Clémence Kress and Wendy A. Bickmore

Genome Res. 2009 19: 1184-1194 originally published online April 23, 2009

Access the most recent version at doi:10.1101/gr.089045.108

Supplemental http://genome.cshlp.org/content/suppl/2009/05/27/gr.089045.108.DC1
Material

References This article cites 34 articles, 17 of which can be accessed free at:

http://genome.cshlp.org/content/19/7/1184.full.html\#ref-list-1

\section{License}

Email Alerting

Receive free email alerts when new articles cite this article - sign up in the box at the Service top right corner of the article or click here.

\section{Affordable, Accurate Sequencing.}

